Subirats, E. (2014). Mito y literatura. México: Siglo XXI editores. Pp. 445.

\title{
MITO Y LITERATURA DE EDUARDO SUBIRATS
}

Orlando Grossegesse

Universidade do Minho

Não é nenhum exagero considerar Mito y Literatura um dos grandes livros que se publicaram recentemente na encruzilhada entre Ciências da Cultura e Literatura. Utilizamos o termo Ciências porque esta obra irreverente e crítica do mainstream se posiciona expressamente em dois contextos, ligados entre si, reagindo (1) à colonização do pensamento pelos Cultural Studies das universidades norte-americanas e (2) ao esvaziamento político e ideológico do ensino e da investigação nestas áreas que se têm revelado sintomáticas de uma despolitização generalizada da vida académica nas sociedades ocidentais, um processo que teve início nos anos oitenta do século XX. Para quem conhece a obra de Eduardo Subirats, filósofo versátil e indisciplinado, tal posicionamento não surpreende porque já se vem expressando, com coerência e frontalidade invulgar nos meios académicos, na vintena de títulos individuais publicados ao longo dos últimos 25 anos, com algumas (re)edições brasileiras mas, curiosamente, nenhuma em Portugal. ${ }^{1}$

Mito y Literatura consiste essencialmente em cinco aulas de hermenêutica literária, autênticas master classes, dedicadas a cinco obras da literatura latino-americana do século XX que - na opinião de Subirats - podem ser consideradas 'clássicas': Pedro Páramo de Juan Rulfo, Yo el supremo de Augusto Roa Bastos, Los ríos profundos de José María Arguedas, Macunaíma de Mário de Andrade, e Grande sertão: Veredas de João Guimarães Rosa. Trata-se de uma análise de

\footnotetext{
*Coordenador de Ciências da Literatura, CEHUM, Universidade do Minho, Braga, Portugal.

${ }^{1}$ Contudo, Eduardo Subirats tem participado em atividades organizadas pelo CEHUM, por exemplo no X Colóquio de Outono, novembro de 2008. (Un comentario sobre el concepto de vanguardia. Diacrítica 24 (3), 2010, 79-86).
} 
criação literária sobre as grandes interrogações de $\mathrm{O}$ que é literatura? (no capítulo inicial) que conduz a uma revisão do relacionamento entre mimese, ficção e mito, rematada no capítulo final.

Já em livros anteriores como A penúltima visão do paraíso (São Paulo, Studio Nobel, 2001) - poder-se-ia referir outros -, Subirats empreende uma análise da modernidade latino-americana, reivindicando-a na sua ambiguidade e riqueza contra as tentativas de subalternizá-la no "argot pós-colonialista, com sua pouco escrupulosa desistorização dos contextos geográficos e temporais procedentes do colonialismo anglo-saxão e sua distintiva pretensão universalista" (2001, p. 127). No ensaio "Las poéticas colonizadas de América Latina" (recolhido no volume com o mesmo título, de 2010) encontramos uma crítica mais completa dos Cultural Studies, dos seus efeitos 'colonialistas' tanto na vida académica internacional como na exportação exotizante da cultura e literatura latino-americanas, crítica essa que constitui sem dúvida a maior motivação para um contraprograma de interpretação tão imponente como o apresentado em Mito y Literatura que nasce do terreno pedagógico dos cursos ministrados por Eduardo Subirats na New York University (NYU), onde é professor desde 1997, e na Universidad de Guanajuato (México).

Outra motivação consiste em contrariar a divisão académica entre filologias em língua espanhola e em língua portuguesa, que prolongada fora de Europa - tende a obstruir uma projeção integrativa latino-americanista. Acrescenta-se ainda a marginalização do estudo das literaturas nas línguas pré-coloniais e dos conhecimentos artísticos e religiosos associados, o qual fica 'arrumado' nas secções de arqueologia e antropologia em vez de se considerar o universo destas culturas milenárias, que conseguiu sobreviver apesar da força violenta e destruidora do colonialismo, no seu contributo para a modernidade: um contributo criativo que abrange uma reflexão crítica sobre a civilização colonial e, por isso mesmo, não pode ser reduzido às dimensões banais de mestiçagem arcaica ou, no argot pós-colonialista atual, sob as categorias de sincretismo e hibridismo. ${ }^{2}$ Muito pelo contrário, no entendimento de Subirats, a modernidade latino-americana deve ser compreendida na

${ }^{2}$ Vd. o Informe para la Academia sobre la revisión de las memorias culturales ibéricas y latinoamericanas, (...), Univ. de Oviedo (Ediuno, 2005, pp. 65-66). 
sua procura da essência do ser humano e da sua preservação que implica um regresso às bases míticas, nomeadamente aos cultos ancestrais da 'Grande Mãe', nas suas mais variadas concretizações, cultos esses que foram soterrados ou desfigurados em nome de uma razão cristã patriarcal. Tal entendimento baseia-se num conceito de cultura de tradição filosófica que difere fundamentalmente da visão racionalista dominante, de raiz kantiana: trata-se de uma linha inaugurada por Vico e Herder e continuada pelos grandes e pequenos nomes da antropologia e das ciências da religião, de J. J. Bachofen a Karl Kerényi, pensadores que têm compreendido a origem e o desenvolvimento das culturas a partir dos seus mitos, deuses e cosmogonias, concebidos como sistemas de integração de todas as expressões humanas.

Esta é a abordagem que guia as interpretações das cinco obras da literatura latino-americana escolhidas, contribuindo para a definição do seu estatuto de 'clássicos' de um novo cânone que desrespeita as categorias de centro e periferia. Podemos exemplificar tal abordagem a partir do capítulo dedicado a Pedro Páramo. O narrador, Juan Preciado, regressa à aldeia de Comala. Está à procura do seu pai incerto e desconhecido: "Me trajo la ilusión". Esta ilusão parte da vontade da sua mãe Dolores, tornando Juan Preciado o seu mensageiro: ele sente a voz duma mãe primordial e cósmica. Até chega a unir-se sexualmente com aquela mãe (na realidade, substituída por outra pessoa), resolvendo o conflito do filho com o pai usurpador da mãe (Pedro Páramo) no instante que desaparece no reino inferior de Comala, engolido pela terra quente e húmida - a união com "el cuerpo de aquella mujer hecho de tierra": "Yo me sentía nadar entre el sudor que chorreaba de ella...".

Sem entrar em mais pormenores da narrativa, o que interessa é a memória de matérias míticas convocadas pela viagem iniciática de Juan Preciado, ao mesmo tempo uma espécie de regressus at uterum (2014, p. 64): trata-se " $¿$ (...) de un Edipo mesoamericano? ¿Tal vez de un Caronte náhuatl? $i(.$.$) un Orfeo que desciende al inframundo para$ unirse mágicamente con una Eurídice de lodo y fuego?" ou devemos antes recordar "que en el códice de Cuauhtitlán se cuentan las hazañas de Quetzalcóatl en el reino subterráneo de Mictlán" (p. 51). 


\section{ORLANDO GROSSEGESSE}

Não há correspondências exatas, unicamente memórias convocadas, apesar de todas as indicações contraditórias, de um material mitológico "desagregado, hibridizado y distorsionado" (p. 53). Não se trata da restauração arqueológica de um mito náhuatl nem da sua transformação em formato surrealista ou real maravilhoso; trata-se, sim, do relato, em registo onírico, do destino de "un típico hijo de una madre típicamente abandonada en un típico pueblo de Jalisco, México" (p. 52). Na abordagem de Subirats, o que interessa é o frágil equilíbrio entre estes símbolos da história profunda das culturas pré-coloniais e o nosso mundo contemporâneo:

Por establecer un término mediador entre una tradición oral arcaica y una escritura moderna, la obra de Rulfo, al igual que la de Arguedas y Guimarães Rosa, y al igual que la de Vicente Huidobro o Mário de Andrade merecen el título de obras clásicas de la literatura moderna latinoamericana del siglo XX. (p. 53)

As referências a outros autores nesta citação estabelecem a ligação a capítulos subsequentes de Mito y Literatura que, tal como esta primeira master class sobre Pedro Páramo, oferecem entradas bem fundamentadas e ilustradas nas dimensões míticas dos romances. Subirats vai além da procura de vestígios de "cultura enterrada" ou "cultura condenada" - conceitos utilizados por Augusto Roa Bastos que expressariam só o caráter subalterno desta dimensão numa lógica colonial, prolongada até ao presente numa taxinomia geopolítica de versões regionais de cultos originais mexicanos, peruanos, etc.. Muito pelo contrário, Subirats continua na linha do pensamento de Karl Kerényi que entende o mito como fundamento do mundo e, ao mesmo tempo, como uma realidade vivida, por estabelecer uma comunicação não só com as origens sagradas do ser mas também com a base primordial da nossa existência. Neste sentido, a viagem de Juan Preciado a Comala é um descenso à casa, ao paraíso originário e ao centro cósmico de Tamoanchan da mitologia náhuatl, misturado - tanto na memória dos camponeses de Jalisco como no horizonte do leitor ocidental comum com o posterior e dominante mito cristão do inferno (p. 68). Admitindo a hibridização como uma espécie de mal menor, a recuperação dos mitos pré-coloniais nesta linha interpretativa corre evidentemente o 
risco de se aproximar de visões românticas, iniciadas no "Gespräch über die Poesie" (1800) de Friedrich Schlegel, quando se fala de uma Nova Mitologia como grande tarefa do século para que a humanidade reencontre o seu centro. Curiosamente, Schlegel está ausente das densas referências bibliográficas de Mito y Literatura. No entanto, a dimensão messiânica ou, dito de forma mais abrangente, a ideia de salvação ou redenção constitui um ponto de reflexão permanente, por se encontrar no cerne da preocupação da modernidade, desde Walter Benjamin a Oswald de Andrade. Já em livros anteriores como o acima citado $A$ penúltima visão do paraíso, Subirats tem vindo a integrar o Movimento Antropofágico na sua conceção de modernidade latino-americana; daí decorre que a inclusão de Macunaíma e ainda de Grande sertão: Veredas, epopeia muito significativa sobre a redenção do homem, nestes clássicos como uma consequência lógica.

Portanto, o que acabámos de exemplificar na interpretação de Pedro Páramo aplica-se a cada um dos cinco capítulos que - cada um com aproximadamente 70 a 90 páginas - mais parecem livrinhos autónomos, contudo, interligados pelo propósito comum. Por exemplo, existem ligações entre os mitos presentes em Pedro Páramo e aquele cosmos sagrado que encontramos em Los Ríos Profundos de José María Arguedas. Não só nos referimos ao culto telúrico da "Gran Diosa Pachamama" (p. 215), que não podia ser erradicado pelos missionários cristãos, mas também ao não-lugar do tempo mítico chamado em quéchua huak'cho (p. 176). A palavra expressa aquela orfandade que Mito $y$ Literatura identifica, já na abertura, como "condición desahuciada en un mundo violento, contaminado y desolado" (p. 27) - que continua a ser a nossa condição no mundo contemporâneo, e cada vez com maior violência. Por isso, o huak'cho é ponto de partida comum de poéticas latino-americanas e europeias, possibilitando abordagens comparativas com Kafka e Beckett, entre outros.

Trata-se de reaprender as raízes da cultura europeia através da literatura clássica latino-americana, uma aprendizagem afastada de qualquer arrogância de dependência e subalternidade, muito pelo contrário no sentido integral de uma literatura mundial que, para além das suas dimensões estéticas específicas, é portadora dum conceito de 
cultura fundamentado em mitos que resistem contra estruturas de poder e violência destruidoras. Portanto, trata-se igualmente de restaurar o diálogo literário e filosófico destas obras latino-americanas, ancoradas no universo de culturas milenárias pré-coloniais, com o pensamento e a literatura mundiais, passando do Bhagavadgita a Leão Hebreu, de Shakespeare a Kafka, da filosofia libertina de Sade ao Fausto de Marlowe e Goethe e até ao Doktor Faustus de Thomas Mann, no âmbito da interpretação do anti-herói Riobaldo em Grande sertão: Veredas como negação de Faustus. O pacto com o diabo, assinado e carimbado com sangue, é substituído por uma misteriosa aliança demónica e ao mesmo tempo não demónica que se converte em certo ritual xamânico, expressando-se na linguagem mais elemental de um "ficar sendo...", de um "eu queria ser mais do que eu...", de "mais força" e "maior coragem" (p. 476), eludindo assim soberanamente o destino de Doktor Faustus de Mann que coincide com os delírios e pesadelos dos fascismos, das guerras e dos genocídios modernos (p. 377). Em vez de partir de relações intertextuais (prováveis), neste caso da receção de Mann por parte de Guimarães Rosa ${ }^{3}$, para chegar a leituras comparadas, Subirats empreende uma espécie de meta-análise de cariz filosófico na linha de pensadores como Karl Kerényi, contudo sem descurar os estudos literários, antropológicos e etnológicos acerca de cada um destas cinco obras e apontando referências cruzadas entre literaturas / mitologias europeias e latino-americanas.

A quantidade de referências que Subirats convoca é tão avassaladora que o leitor fica inevitavelmente invadido pelo sentimento da grandeza do património imaterial da Humanidade, sentimento no entanto atravessado pela angústia da sua destruição, seja material seja por processos de amnésia que dizem respeito à própria escrita e possível recepção de um livro tão monumental como Mito y Literatura. No epílogo, Subirats conclui no tom que lhe é próprio, quando comenta a recusa por parte de Tusquets Editores de publicar Mito y Literatura,

\footnotetext{
${ }^{3}$ Não definitivamente comprovada conforme Marcel Vejmelka (2005). Kreuzwege: Querungen; João Guimarães Rosa Grande sertão: veredas und Thomas Manns Doktor Faustus im interkulturellen Vergleich (Berlim: ed. Tranvía, p. 233-234). A leitura comparada empreendida por Vejmelka (2005, pp. 215-441) teria sido um contributo valioso para este capítulo da obra de Subirats.
} 
justificada pelo interesse reduzido, meramente académico ("poca gente sabe ya quién es Mário de Andrade o Guimarães Rosa"):

Para la lógica mercantil que rige las industrias culturales algo así como una literatura clásica latinoamericana del siglo XX es una apostasía, y su hermenéutica literaria una actividad sacrílega, cuando no directamente una agitación intelectual subversiva. El concepto de cultura que esa lógica detenta se confunde crecientemente con el de barbarie. (2014, p. 441)

O nosso atrevimento inicial de considerar Mito y Literatura um dos grandes livros que se publicaram recentemente na encruzilhada entre Ciências da Literatura e da Cultura deve-se precisamente à sua virtude de recuperar a poética de um novo humanismo alicerçada nas referidas cinco aulas de hermenêutica literária, escrito num estilo acessível a um leitor erudito e interessado. Todas elas dão voz a um enquadramento político, no sentido abrangente da palavra: um alerta para os professores que se dedicam ao ensino e à investigação no campo das Ciências Humanas de não permanecerem como meros 'cavaleiros andantes' alheados no seio de sociedades iletradas que sofrem tendências cada vez mais fortes de desenraizamento transcendental devido aos processos imparáveis de destruição das memórias culturais e, com isto, dos vínculos entre os seres humanos que elas sustentam, $\mathrm{e}-$ dos sonhos de um mundo melhor. 